\title{
Lapurdum
}

LAPURDUM Euskal ikerketen aldizkaria | Revue d'études basques |

Revista de estudios vascos | Basque studies review

$9 \mid 2004$

Numéro IX

\section{Dotrina, erretorika eta erudizioa Mogelen erlijio liburuetan}

Xabier Altzibar

\section{OpenEdition \\ Journals}

Édition électronique

URL : http://journals.openedition.org/lapurdum/764

DOI : 10.4000/lapurdum.764

ISSN : 1965-0655

\section{Éditeur}

IKER

Édition imprimée

Date de publication : 1 novembre 2004

Pagination : 23-38

ISBN : 2-68781-376-X

ISSN : $1273-3830$

Référence électronique

Xabier Altzibar, «Dotrina, erretorika eta erudizioa Mogelen erlijio liburuetan », Lapurdum [Linean]

9 | 2004, Sarean emana----an 01 mars 2009, kontsultatu 19 avril 2019. URL : http://

journals.openedition.org/lapurdum/764; DOI : 10.4000/lapurdum.764 


\title{
Dotrina, erretorika eta erudizioa Mogelen erlijio liburuetan
}

\author{
Xabier ALTZIBAR \\ Euskal Herriko Unibersitatea
}

\section{Kristau dotrinaren irakaspena}

1. Juan Antonio Mogel, Markinako apaizak (1745-1804), anaia-aita-aitonak mediku zituenak, bere burua arimen medikutzat zeukan ; arimazaintza eta arimak salbatzea, bere egitekotzat. Horretarako liburu onak idaztea zela onena uste zuen. Hain zuzen, haren idazlan gehienak kristauaren eginbideei buruzkoak dira. Horien artean mamitsu, mardul eta azalpenean oparoenak aipatuko ditugu lehenik ; bizi zela, ondokoak argitara zituen :

1801 : Confesio ta Comunioco Sacramentuen gañean Eracasteac (Iruñea : Ezquerro). Haren iragarpentzat argitara zituen 4 orrialde, data eta inprimatzailearen izen gabe : Prospecto de una Obra bascongada intitulada Confesio ta Comunioco Sacramentuen gañean Eracasteac.

1803 : Confesino ona edo ceimbat gauzac lagundu biar deutseen Confesinuari ondo eguiña iza teco (Vitoria : F. Larumbe).

Argitaratzeko prest utzi zuen ondokoa : El Catequista Bascongado-Cristau Eracasle Euscalduna: Irugarren zati edo partea : Jangoicoaren Legue, ta Eleizaco Mandamentuen gañean. Bi argitaraldi izan zituen (Labayru Ikastegia-BBK, Bilbao, 1993, A Arejitak prestatua / Bonaparte ondareko eskuizkribuak, Gipuzkera-4, 241259, Deustuko Unibertsitatea-Euskal Ikaskuntzen Institutua, 1993, R. M. Pagolaren ardurapean). Beraz galdu bide dira (agian ez !) CBren I, II, IV zatiak, baita III.eko zati handiena ere, Jainkoaren Legeko azken bost mandamentuena eta Elizakoena ere ; hortaz, III. zati horretako beste liburuki bat edo bi. Nolanahi ere, heldu zaigun parteak osatzen du Mogelen dotrina azalpen luzeena.

Ondoko dotrina azalpenezko liburua ere argitaratzeko prest utzia dirudi, hitzaurrea baitu. 1987an argitara zen : Cristaubaren Icasbidea edo Doctrina Cristiana (Bilbo : Euskaltzaindia, Fr. L. Villasantek prestatua). Argitalpen honetan, beste atal bat gehitu zitzaion, beste kodize biki eta aurreragokoa dirudien batena : Cristinaubaren Eracuspena edo Doctrina Cristiania (Labayru Euskal Bibliotekan, Derio, Bizkaia). Dotrina laburrak ordea, ez ditugu aipatuko.

Dotrina-liburuoz gainera, aipagarri da Vida edificante de la sierba de Jesus Sor $D^{a}$ $M^{a}$ Ignacia de Sta $M^{a}$ Magdalena y Ubilla 1797-1798 inguruan idatzia, nahiz guztiz bururatu gabe, 1927an argitara zen (Burgos: Aldecoa). 
Mogelen platikak edo sermoiak, 1775 ingurutik aurrerakoak, 1991an argitara zituen Arejitak (Memoriae L. Mitxelena Magistri Sacrum, J.A Lakarra ed., ASJU, Gehigarriak, XIV, 277-300).

1790 ondoren itzulia bide zuen Mogelek Pascal-en pentsamentuen zati bat, Azkuek 1899an argitaratua (Euskalzale, III), Pa scal-en Gogamenak izenburupean.

Aipatu idazlanak laburtzapenez izendatuko ditugu, hurrenez hurren : CC, Prospecto, CD, CO, CB, CI, Vida, Pascal, Serm.

Artikulu honetan bereziki El Ca tequista Bascongado-Crista u Eracasle Euscalduna, hots, CBri buruz mintzatuko gara, dotrina-liburuen artean hori delakoan mamitsuena, baita hizkuntza eta erretorikaren aldetik ${ }^{1}$. Alde batera uzten ditugu dotrina laburrak, baita erlijio gaiei buruzko bertsozko kantak eta, jakina, Peru Abarka, Versiones Bascongadas de varias arengas latinas, alegi edo ipuinak eta gutunak. Testuen aipamenak hitzez hitz jasotzean, lehen ediziotik eginak izan arren (Vida-koak ordea, eskuizkributik), oraingo ortografiaz jantzi ditugu, formak eta ahoskera errespetatuz; berdin jokatu dugu gaztelerazko testuen aipamenetan.

2. Mogelen platikak edo sermoiak irakurraldiak ziren (Mendibururenak bezalatsu), gehientsuak Jesusen Bihotzaren Markinako Kongregazioan irakurtzekoak. Oso goiz hasi zen horiek idazten, 1775 inguruan ; gero horiek berak urte luzeetan predikatu zituzten Markinan, Mogel hilda gero, adib. 1810, 1820, 1830.eko hamarkadetako urteetan. Kontua da euskarazkoak eta idatziak direla, ondo idatziak gainera, eta hori, euskarazko sermoiak idatzi eta gordetzea, XVIII. mendean hegoaldean eginiko urrats handia izan zela uste dut, ordura arte ez baitziratekeen euskaraz idazten. Nahiko ugariak dira XVIII. mendeko euskal sermoi idatziak, gorde direnak ere. Larramendi, Kardaberaz eta Mendibururen etsenplu edo eraginari esker gertatu bide zen hori. Ez bide zen, ordea, sermoirik argitaratu XVIII. mendean, oraingoz ezagutzen dugunik bederen, ez Arandaren debekua baino lehen eta ez ondoren. XIX. mendean argitaratuko ziren, irakurtzeko egokituz eta liburu itxura emanez.

3. Mogelen liburuek, argitaratu nahiz argitaratu ezinik gelditu zirenek, haren garaikide Añibarrorenekin eta orpoz-orpo zerraizkien J.B. Agirre (1803, 1850), Fr. Bartolome (1816, 1817, 1819) eta Fr. Pedro Astarloaren (1816, 1818) liburuekin batera, segida eman zioten Mendiburu eta Kardaberazek XVIII. mende erditsutik aurrera abiarazitako bideari.

Gainera, Mogelen liburu batzuk arrakastatuak izan ziren, ale kopurua edo argitalpenak kontuan hartuta. CC-ri buruz dio :

"Jakin dot abade jaun askok irakurten ditubezala Elexetan, ta nekezale ez gitxik euren etxeetan" (CO hitzaur.).

“Ikusi dot zelan zabaldu dirian milla bat liburu Naparroa, Gipuzkoa, ta Bizkaijan" (ibid.).

COk berak edizio ugari izan zituen XIX. mendean; dotrina laburrek ere bai. Mogelek bere liburuak Iruñean, Gasteizen eta Tolosan argitara zituen. Bizkaitarra izan arren, erlijio-liburu mardulenak gipuzkeraz idatzi zituen $(\mathrm{CC}, \mathrm{CB})$; bizkaieraz $\mathrm{CO}$ Kardaberazen bideari jarraitzen dio euskalki bata eta bestea, eta, euskalkion barruan, erdialdeko hizkera edo formak erabiltzean, euskalkia "nahastu gabe" (CC hitz. XIII). Mogelek Kardaberazen eskaerari erantzun zion :

1 - Arejita, Aren edizioko testua hartzen dugu aintzat. Artikulu honetan landutako puntu ugari, batez ere erretorika-baliabideei buruzkoak, hark ere aztertuak ditu lehenago, aipatu edizioko hitzaurrean. 
“Jaungoikuaren ontasunari eskatzen diot Bizkaiko biotz nobleren bati ango era, edo dialektoan zeruko doktrina ta ejenploen libruak ateratzeko arren argi zeloz, ta gogoz bete bat eman diozala." (Kardaberaz , Euskeraren berri onak, ap Mog CO hitz 5).

Izan ere, Kardaberaz eta Mendibururen liburuak deboziozkoak ziren ; Mogelen gehienak ordea, kristau dotrinaren irakaspenezkoak, hots, kateketika liburuak.

4. Mogelek bere erlijio-idazlanak Frantziako Iraultzaren (1789) ondoren idatzi eta argitara zituen. Iraultzaren ondoren, Eliza Katolikoak erlijio katolikoa indartu nahi zuen liburuen zabalpenaren bidez baina dotrinaren ikuspegi edo interpretazio estu bat ezarriz eta zentsura zorroztuz : adib. A. Boggiero-ren Pensamientos de Pascal sobre la religión (Zaragoza, Viuda de Blas Miedes, 1790), Pascalen Gogamenen gaztelaniazko itzulpenean -horren itzulpena baita Mogelena-, Pascalen zati bat moztua eta galbahetua izan zen ("depurada de todo error", argitaratzailearen oharrak dioenez). CCn eta CBn fedearen eta dotrinaren garbitasuna aldarrikatzen du Mogelek. Lehenbizikoaren iragarpenean dio :

"El enemigo común hace mayor guerra a los hijos de la Iglesia con la falsa e imaginada penitencia, que con las más sangrientas persecuciones de los tiranos." (Prospecto).

Eliza Katolikoak Trentoko Kontraerreformaren bideari heltzen dio berriro. Horren eragina nabarmena da CB eta Vidan, eta, Trentoko Katezismoa gutxitan aipatzen badu -XIX. mendeko dotrina-liburuen idazleen eretzean-, horren arrazoia bilatzeko, Mogelen jakintza-iturriak eta irakurketak Frantziako Iraultza baino lehenagoak ohi zirenak ote diren aztertu beharko da.

5. Mogelek bere liburuak idatzi zituen, alde batetik, elizgizonentzat, euskarazko liburuak irakurtzen ohitu zitezen lagungarri (CC hitzaur VII); eta bestetik, jende-xehearentzat, hots, aita-ama familiakoentzat, batez ere nekazalentzat (Prospecto).

“Abade jaunei jagoke erosi eragitia onelango liburubak euren errijetako nekezale irakurten dakijenai. (...) Sermoi asko daukez liburu onetan, ta besterik ezin dabenian Kura jaunaak irakurten baditubez elexan emen dagozan irakaste edo dotrinak, eukiko dabee poza ikusteko (...)" (CO hitz. 7).

Eta argitara zituen, hain zuzen, etxean nork bere buruarentzat edo familian ez eze, elizan jendaurrean ahoz ahoz irakurtzeko (Fr. Bartolome eta Fr. P. Astarlorenak bezala; J.B. Agirreren Erakusaldiak ordea (1850), irakurtzeko moldatu predikuak ziren).

"Si tuvieran libros que descubriendo los errores prácticos, quitasen las ignorancias de la baja plebe, podrían a lo menos leer las doctrinas catequísticas en la Iglesia" (Prospecto).

6. Kristau dotrinaren azalpena eta irakaspena (instruzioa, Mogelek berak dioenez, CB 246) da Mogelen erlijio liburuen xede nagusi. Alegietan hala baitzen, arrazoi gehiagoz erlijio liburuetan. Kristau dotrinaren "erakaste edo esplikazio osoak" eman nahi ditu (CC hitz. VIII, IX). CC eta COn konfesio eta komunioko sakramentuen inguruko dotrina azaltzen du; $\mathrm{CBn}$, edo gorde den hirugarren zatian, zehatzago esateko, Jainkoaren Legeko lehen bost mandamentuen gainekoak. CB liburuaren egiturak ere, hots, G(aldera) laburra eta ondoren $\mathrm{E}$ (rantzun) luzea, erakusten du ez dela benetako elkarrizketa, katekistaren irakaspena baizik. 
7. Mogelen ikasketak eta bizitza gizartearen heziketara bideratuak izan ziren. Kalataiud-en (Zaragoza) jesuitekin eginiko ikasketak, 18 urte artekoak, ez ziren nolahalakoak izan, hautuak baizik. Kalataiud hiriko Nobleen Erret-Mintegiak etxe kapare edo etxe oneko gaztetxoak hazten eta hezten zituen. Zaldun kristau izaten irakasten zitzaien : jaun gisa janzten ziren, dantza, musika eta esgrima ikasten, baina familiaren eta adiskidetasunaren goxotasunik gabe, eguneko ordu guztiak otoitzean edo ikasten, eta bestelako libururik irakurri ezinik. Bertute, gizalegea eta letrak irakasten zitzaizkien. Ikasketak ziren helburu nagusi ; ikasle ona izatea beharrezkoa zen, arima salbatzeko ere. Ikasleak diziplina handiz heziak ziren, gogoa beti jakintza eta izpirituko larretan alha, lohikerian ez erortzeko asmoz. Hots, guk aztertu ditugun Mogelen 18 urte arteko ikasketak kontuan hartuz, esan dezakegu jesuitek beren ikasleak gidatzen eta bideratzen zituztela gizartean norbait izateko eta are gizartea hezteko (Altzibar : 1992 : 117-128).

Mogelen etorki, ikasketa, jakintza, izakera alderdi batzuetan ageri da ez zela jende apal xumeetarikoa, gizartean zuen egitekoaz jabetua zela, hots, gizarte euskaldun eta maila guztietako jendearentzako -batez ere apalekoentzako- irakasle, hezitzaile, hots, arimazain izan behar zuela.

8. Mogelek konfesio, komunio eta Jainkoaren Legeko Aginduen azalpen zehea eta maila aski gorakoa ematen du, helburu praktiko batekin : Euskal Herriko ohiturei aplikatu eta kasu bakoitzean noiz-nolakoa den bekatua, astuna edo arina, adierazi. Batez ere Jainkoaren Legeko Aginduen kontrako hutsegiteetan (CC hitz. IX).

"Se debe manifestar (dejando cuestiones turbadoras y disputas porfiadas de autores) cuándo se peca, cuándo no ; cuándo mortal, cuándo venialmente ; porque hay en ello tales ignorancias, que lo bueno hacen malo, y lo malo bueno ; lo grave confunden con lo leve." (Prospecto). "El Autor de esta Obra ha procurado seguir este método práctico en las muchas doctrinas, pláticas, o discursos catequísticos que contiene (...)" (ibid.).

Beti Jainkoaren, Elizako doktoreen eta santu-santen hitza aipatuz ; beti egiaren izenean gezurraren eta heresiaren kontra, horiek gudukatzeko Inkisiziora jo behar dela esanez.

“Onelako blasfemiatzarrak esan badira ezaueraz, ta ala dalako sinistearekin, dira herejia osoak, ta salatu bihar dira esanlak Inkisiziora, ta galdetu lehenago gizon ixil, ta jakitun bati zer entzun duen." (CB 120).

“Doktrina gaiztoak ereiten dituztenak salatu bear dira Inkisiziora, ta entzuten duteenak zerbait esan dala Fedeko doktrinaren kontra, itundu edo konsultatu bear dutee konfesore jakitun batekin." (CB 311).

Egitez, Mogelek berak Inkisizioan salatari lanetan jardun zuen, ustez kristau dotrinaren kontrakoak ziren liburuak, eta Frantziako Iraultzaren aldekoek Bizkai aldean hedarazten zituzten kazetak salatzen (1792). Jakina da ere Inkisizioan liburuaztertzaile titulua eskatu zuelarik (1794), titulu hori eman ziotela, emaileek bazekitelako Mogelek kristau fedearen alde oso zorrotz jokatzen zuela (Garate : 1935 : 227-229).

9. Mogel garaiko bizimodu eta gertaeren kasuistikan oinarritzen da, Eskritura Santuko eta Elizako Doktoreen irakaspenak aplikatuz. Horretarako euskal gizartean, bereziki baserri girokoan, haren arabera ohitura txar eta gaiztakeria direnak naharo deskribatzen eta garrazki gaitzesten ditu. Berez ohitura txar ez direnak ere, egungo ikuspegitik bederen, ia gaitzesteraino heltzen da, adib. dantza 
lotuak, "nahasiak" deitzen dituenak. Sinesgaitza dirudi euskal dantzen gaitzespen horrek, XVIII. mendean dantzen ikasketa hezkuntzako partetzat hartua baitzen (hala ageri da Rollin-en Ikasketen Tratatuan edo Mogelen ikaskuntzetan, esan dugunez). Hona Mogelen adibide borobil eta harrigarri bat :

“O euskaldun maiteak ! Lotsatzen naiz esan bearraz. Ezta kristau erri, ez hereje, ez jentiletan arkituko plaza, kale, bide, ta leku agirietan anbeste lasaitasun, lotsagabekeria, apa laztan ta eskuka zatar, nola ekusten dan euskaldunen artean. Urte askoan bizi izan naiz erdaldunen artean; ez det inoiz ekusi kale, bide, ta leku agirietan eskuka ta tentatze txar bat gizasemeak egiten emakumeari. Dira lotsati edo grabeak. Berriz euskalerrietan eznaiz atrebitzen irtetera pesta egunean paseo bat ematen, zerren ekusi oi diran zatarkeria asko. Nondik dator ? Jendea lasaitzen da danzako soñu, algara, botaka, mokorka, ta esku erabilliekin, ta guero egin oi dira lotsagabe eskuka zatarrak." (CB 223).

Horrelakoak Euskal Herrian bakarrik gertatzen zirela ez da erraz sinesten. Gai hori aitzinago Palacios, Añibarro eta batez ere Fr. Bartolomek erabili zuten, ikuspegi moral huts eta hertsitik begiratuz (Euscal-errijetaco olgueeta, ta dantzeen neurrizco gatzozpind uba. Iruñea :1816). Humboldtek ordea, halako ikuspegi moralistatik urrunduz, euskal dantzak euskal erakundeen ikuspegitik zuten balioa azpimarratu zuten.

Nolanahi ere, irakasteko bideen artean, gaitzespena nagusi da Mogelen dotrina azalpenean, ohitura eta etsenplu on edo ereduen gainetik.

10. Jakina, Mogelen dotrina-liburuetan Mogelen garaiko ideiak, hezkuntzakontzeptuak eta hitzak ageri dira, gure egunetan erabiltzen ez direnak : lotsa eman (gurasoek seme-alabei ; lotsa bizkaiera-gipuzkeraz 'errespetua, bereziki nagusiari zor zaion larderia') ; la saitasuna (modestiarik eza : luxuriaren adibide bat) etab. Mogelen garaiaz geroztik, urak bide egin du, baina moral hertsi hori geuk ere ezagutu izan dugu geure haurtzaroan (1968ko Maiatzeko iraultzara arte, gutxi gorabehera : hona nola historia itzulika ari den baita).

Mogelen dotrinako puntu batzuk ohargarriak dira : adib. Goragokoei obeditzea, esaterako erregeari, gaiztoa bada ere :

“Beeragokoak obeditzea goragokoai, pagatzea zoorrak, honra, lotsa, ta petxuak. Errege, ta beste agintariak gaiztoak badira ere, agintzen ez dutenean Jangoikoaren kontrako gauzarik, bear dute honra ta obedienzia." (CB 264).

Edo besteri bizia kendu dionari berari bizia kentzea (eta hori Jainkoaren izenean !) :

“Esan nai du Jangoikoak, kendu bear zaiola bizitza Justiziaren bidez, lagunari bizitza kendu dionari. Eta gu poztutzen bagera gaiztagiñak deserritzen, karzelatzen, ta urkatzen dituztenean, ez degu bekaturik egingo Justiziaren amorez bada, ta ez gere gorrotoz" (CB 282).

Ohargarria da ere apaizaren egitekoa eztabaida eta liskarretan : ararteko izatea.

“erakatsiko dizut nik zer egin kalteak egin dizkitzuenean. (...) Zoaz gero erriko kura, edo sazerdote on bategana, esan zaozu zer gertatzen zatzun, nolako kalteak egin dizkitzuen, ta onek artuko du bidea eskribauetara joan gabe bakean gauzaak konpontzeko." (CB 296).

11. Beraz lekukotasun balioa dute Mogelen dotrina-liburuek, bai Christina ubaren Eracuspena-k bai CBk (zer esanik ez, Peru Abarkak). Izan ere, garaiko bizimoduko kasu, ohitura edo gertaerei dotrina aplikatzerakoan, Mogelek xeheki kontatzen edo 
deskribatzen ditu. Etnografia aldetik duten balioa aipatua izan da (Altzibar : 1992 : 154 ; Arejita : 1994 : 17-21). Adib., herri sinesteei dagokienez, badirudi Mogelek, alde batetik Eliza Katolikoaren zerbitzari fidel eta obedient, eta bestetik arrazionalista gisa, haiek ez onesteko, ezta ulertzeko eta bai errazegi kondenatzeko joera duela ${ }^{2}$.

Beste xehetasun jakingarri batzuk ere aurki daitezke : konbentzioko gerrarenak (CB 93, 154) ; autobiografia-zerzeladak ${ }^{3}$, edo hizkuntzari dagozkionak (adib. juramentu eta maldizioen euskal adierazpideak, CB 165).

12. Mogelen erlijio liburuen artean, bada bat berezia : Vida edificante de la sierba de Jesus Sor $D^{a} M^{a}$ Igna cia de Sta $M^{a}$ Magdalena y Ubilla. Gaztelaniaz eta monjentzat idatzia da eta dama mundutar bat Mogelek nola onbideratu zuen kontatzen du. Mogelen biografia da zati gehiena, parte bat M. Ignazia Ubillaren beraren autobiografia, haren gidari izpiritualak, Mogelek, agindu baitzion idazteko ${ }^{4}$.

Aszetika eta mistika liburu bat da. Sta Teresaren aipamen franko ageri da, eta batez ere Done Joane Kurutzekoarenak. Jainkoaren eta debotoen arteko maitasunaren topikoa ageri da, hots, Jainkoarekiko ezkontza (kristau komunioaren metafora). Done Joane Kurutzekoaren liburua Espainiako kontraerreforman erreferentzia-obra da.

Santu eta santek beren bizitza kontatzearen balioa aipatzen du egileak bai liburu honetan (S. Agustin, Sta Teresaren ereduak), bai CBn (ik. Erudizioa atala). Santuen bizitzak idazteari dagokionez, Kardaberazenak aipagarri dira ${ }^{5}$. Bestalde, emakumeen instruzioaren eta beren bizitza konta zezaten ardura eta ia obsesioa aspaldikoa zuen Mogelek, Inkisizioak auziperatzean ere (1779) ezagun baitzen. Mojek latin ikas zezaten ere nahi zuen (hori bera ageri da Rollin-en Ika sketen Trata tuan). Izatez, mojak jende xehea baino jakintza-maila handiagokoak izan ohi ziren.

Arreba M. Ignazia Ubillaren bizitza dotrina, irakaspenetakoaz bestelakoa tonu erretoriko gora eta harroan idatzia da. Irudiz betea, gainera. Ignazia Ubillak -Mogelen hegatsez- bere gida izpirituala deitzen du ("mi Director", "mi Guia", "mi Conductor", "Piloto". Ez ote dago harrokeria puntu bat hor ?). Gero bada hemen misterio ilunsko bat : Mogel, santu hotsekoa omen zelakoa : hain zuzen 1927an

2 - "Erakaste IV Nola ausitzen dan Jangoikoaren legueco mandamentu au Supersticioco gauzaaquin" (CB 99-111). Sinesteak aipatzen ditu : begizkoa egin (CB 104), haurtxoari kutunak ipintzea (CB 104) ; kurutzearen seinaleak (CB 105) ; aztuak eta salutatzaileak (CB 107, 108). Horiek dira "alde batetik eraqueria utsak ta bestetik superstizio edo sorginkeria usaia duteenak" $(108,109)$. Salutatzaileen aurka ari da eta justiziaren kontra protestatzen du, halakoak deserriratzen ez dituztelako (CB 189-190).

3 -Hiru aztu ezagutzen zituela (CB 107). Egilea nolakoa den garbi ageri da testu batzuetan : nola bere onetik ateratzen duten gauza batzuek, adib. txakurrak elizara eramateak (CB 192) ; "nere buru-iritzia" (CC hitz. 1). Vidan ere egilearen bizipen zenbait kontatzen dira (65). Arreba Ignazia Ubillak dio, negar eta negar egin zuela Mogelek hura onbideratzeagatik (Vida 30).

4 - “(...) la adjunta Vida, aunque es biografía, también es autobiografía. En efecto, en este libro se ofrece al lector un traslado literal de lo que sobre su alma y conversión escribió por obediencia la misma interesada." ("Al piadoso lector" hitzaurrea, 'La Comunidad' (de Religiosas Mercedarias de Marquina) izenpetua.

5 - 1882an argitara zen Ama veneragarri Josefa Sacramentu guciz santuarena ceritzanaren Vicitza eta Vertuteac. Tolosan : Eusebio Lopez-en moldiztegian.

Azpeitiko erri chitez noblearen gloria paregabeac edo Aita San Ignacioren bicitza laburra Jesusen Compañiaco Aita Agustin Cardaveraz veneragarriac escribitua. Tolosan F. Muguerzaren moldiztegian, 1901.

Mogel Ignazia Ubillaren onbidezko bizia idazten hasi zen urte berean (1797) Bartolome Pou Mogelen filosofia irakasle ohiaren obra bat argitara zen Erroman, latinez, antzeko izenburuduna, gaztelerazko edizioarena hau izanik : Vida de la Beata Sor Catalina Tomas religiosa agustiniana en el monasterio de Sta Ma ria Magdalena en Palma. Escrita en Roma en cuatro libros por el abate D. Bartolome Pou y destinada à los mallorquines sus paisanos (Sommervogel, Bibliothèque, 1119). 
liburu gisa argitaratu zelarik, esaten da egilea dela “Don Antonio Moguel, apellidado “El Santo"”.

\section{Erretorika}

1. Mogel predikalaria, platika idazlea eta beti idazle erretorikoa izan zen, literaturidazlanetan ez ezik (Peru Abarka, Ipuinak) erlijio-liburuetan ere (CB, Vida etab.). Irakaspena du helburu ; erretorika, tresna. Estilo gogoa nabaria da haren liburuetan, hura dateke hegoaldean, erlijio-liburu idazleen artean, literatura-lanak idazteaz gainera (Peru Abarka, alegiak, Versiones Bascongadas), erlijio liburuetan ere tresna erretorikoak agian gehien lantzen dituena.

2. Idazle erretoriko gisa, ondo idatzitako liburuak nahi zituen :

"ez da berdin oen gañean bear bezela itzegitea agirian, ta bestelako gauzeetan" (CC hitzaur. VII)

(baserritarrek) "ez lukee jakingo nola zuzendu hitzak gauza goratu eta beren gañetikoetan" (ibid.).

Mogelen eliz hizlaritzak (gogoan har bedi liburu elizan irakurtzekoak ere bazirela) eta oro har, euskal tradizioko hizlaritzak, gauzak apaintasunez eta dotoreziaz adierazten jakin izan duela uste dut. Predikalaria edo katekista apaintasunez eta dotoreziaz mintzatzea, irakasterakoan gauzak argi adieraziz ez ezik atsegin emanez, lege zen garai hartako ikasketetan. Hori ageri da garbi Rollin-en ikasbidean ${ }^{7}$. Ordea, egun, apaintasuna eta dotorezia, greziar erretorikalariek finkatu lege hura, ez bide da gehiegi kontuan hartzen, tamalez.

3. Ahopaldi nasaien erretorika da harena, ohikoa euskal sermoigileen tradizioan. Aldiz, sententzia gisako esaldi laburrak gutxiagotan ageri dira (CB 86) ; halaber esaerak (ik. CB 31, Arejitaren hitzaur.). Baina askotan latinezko aipamen laburrez zirtatzen du azalpena, alegietan euskarazkoez bezalatsu.

4. Mogelek ongi zekien estiloak eta hizkuntza-mailak bereizten eta entzuleei egokitzen. Haren idazlanetan bada -irakurle-entzuleak nolako, estilo maila halakomaila goragokorik (Peru Abarka, Versiones Bascongadas, Vida) eta beheragokorik (erlijio-liburuak), erretorikalariek eta Rollin-ek berak irakatsi bezala ${ }^{8}$. Hizkuntzari dagokionez, esaterako, erlijio-gauzetan korritzen zuten mailegu-hitzak -eta ez garbizalekeriaz asmaturiko hitz berriak- erruz erabiltzen ditu.

6 - Vida edificante de la sierva de Jesús Sor María Ignacia de Santa María Magdalena y Ubilla, religiosa profesa y de coro en el convento de las mercedarias de Marquina, escrita por el párroco de Santa María de Jemein Don Antonio Moguel, apellidado "El Santo". Imprenta Aldecoa. Burgos. 1927.

7 - Livre V Des trois genres d'éloquence. Chap. I. De l'éloquence de la chaire. Art. I. Premier devoir du prédicateur : instruire, et pour cela parler avec clarté. Combien la clarté est nécessaire dans les catéchistes. /Second devoir du prédicateur : plaire, et pour cela parler d'une manière ornée et polie. /Troisième devoir du prédicateur : toucher et émouvoir par la force du discours ceux à qui il parle.". Rollin, Charles : Traité des études ou de la ma nière d'enseigner et d'étudier les Belles-Lettres. Paris, L. Hachette, librairie de l'Université, rue Pierre-Sarrazin, 12, etc. 1841. Rollin-en liburua XVIII.m. erdia baino lehenagokoa da.

8 - Libre IV de la Rhétorique. Chap. III. Art. I. Des trois différents genres ou caractères d'éloquence : I. Du genre simple. II Du genre sublime. III Du genre tempéré.

Rollin ezagutzen zuen Murgak eta ezagutuko zuketen J.A Mogelek eta haren iloba Bizentak. Hona, adib. J.M. Murgak Humboldti diotsona, Mogelen Versiones Bascongadas-i buruz: "hube de cansar de nuevo al mismo amigo, rogándole que me tradujera en ambos dialectos vizcaíno y guipuzcoano, y con la mayor actitud que permitiera el genio de ellos, las dos oratorias de Damocles, el favorito de Dionisio de Siracusa, y del maestro de los niños faliscos, que por su sencillez recomienda y copia Rollin en el Tratado de los Estudios.", Garate, J., La época de Pablo Asta rloa y Juan Antonio Mo gel, Bilbao, Imprenta Provincial de Vizcaya, 1936 ; A Arejitak ere berrargitaratua, "Juan Antono Mogelen "Versiones Bascongadas", Litterae Vasconicae, 9, Labayru Ikastegia, 2004, 81. or. 
"Sobre todo las voces eclesiásticas y religiosas que se han comunicado a todos los idiomas, en que se ha publicado la religión, deben permanecer, dice Larramendi, sin la novedad que confunda al pueblo acostumbrado a oir y entenderlas. Pero también es un abuso intolerable el que se hable en la Iglesia un idioma barbarizado, y monstruoso robando al idioma castellano multitud de voces que no entiende la plebe baja." (Prospecto).

"ez dot janziko jaiegunetako soñokuakaz : esan gura dot, ez dodala irakatsico noraño elduten dan bere ugaritasuna berbeetan." (CO hitz. 3).

"euskerak dauzkanean itz ederrak, guzien aoetan dabiltzanak, zertako da erdera mordolloan jardutea ?" (CC hitz. XII).

Hau da, Peru Abarka eta Versiones Bascongadas liburuetakoa baino askoz apalagoa baina errealagoa da CBko euskara, hain zuzen aberastasun eta garbitasuna erakustea edo haren apologia egitea ez duelako helburu. Erlijio-liburuetan erdibidetik jo zuen beraz, Kardaberazek bezala, Mendibururenak bezain garbiko hitzak ez erabiliz. Eta gero Mogelek beti gauzak oso argi azaltzen daki.

5. Mogelen erretorikaren alderdi garrantzitsu batzuk aztertuko ditugu ondoren : argumentazioan Liburu Santu eta Elizako Irakasleek duten pisua, etsenpluen kontaera, irudi, konparazio eta deskripzioen indarra, entzuleekiko elkar aditzea laguntzen duten figurak, hizketa estiloa eta hitz-, hots- edo idazkera-egiturei dagozkien figura batzuk.

Argumentazioa batez ere autoritateen aipamenen bidez egiten du, gertaera eta etsenplutxoen kontaerak lagunduta. Aipamen ugariek osatzen dute bizkarrezurra. Argumentazioa nasaiki, kontraargudioei erantzunez, egina. IK. III. atala, Mogelen erudizioari buruzkoa.

6. Argumentuen anplifikazioa bi bidetatik egin ohi zen : bata etsenpluenetik, bestea irudi eta konparazioenetik. Mogelek ere irakaspena etsenpluekin eta etsenpluen bidez nahi du. Etsenpluak argumentazio mota tipiko bat ziren : adib. Pou-ren eskuliburu aipatuan etsenpluak (exemplum) aipatuak dira silogismo, entimema eta dedukzioarekin batera (Institutiones..., Lib. XII, cap. IV). Etsenpluak izan daitezke : esandakoaren adibideak edo ilustrazioak, edo etsenplu on edo eredugarriak eta txar edo antiereduak. Hizlaritzan, hitzaldiaren egituraketa edo dispositio delakoan narratio partea osatzen zuen etsenplu edo gertaera horien kontaerak.

Etsenpluen balioaz jabetua zen Mogel :

“Buruz ondo dakiten mutiltxo neskatxak asko aurreratuko dira kura edo erretora jaunak egiten duen esplikazioa enzunaz. Ejenplotxoren bat enzuten badu ipuiak ikasten dituzten erraztasun ta pozarekin ikasiko dituzte ; kontatuko dutee etxean (...)" (CB 248).

“Nork esan bada zenbat anima aldatu diran bekatutik Jangoikoaren aldera enzunaz beste gabe ejenplo edo gertaera mirarizkoren bat ? (...) Au dakite misionari, ta anima billa dabiltzan konfesore guziak. Onelako ejenploak enzuten dituzte nekazariak ao zabal, ta atenzio andiarekin; ejenploa bukatzean asitzen dira Jesuska, larritzen dira beste ainbeste gertatu ez didin berarekin, daramate arantza biotzean, erasten zaizte gertaera guziak, kontatzen dituzte etxeetan joan etziranen aurrean, ta Jangoikoak berak bakarrik jakin dezake, zenbat on dakarren predikatze erraz, ta humill onek. Tito Libio, Plutarco, ta onelako mundu jakitun batzuek zerbait kontatzen badute, sinisten zaie. Berriz testigu obeagoetatik datozen ejenploak, ipuitzat dauzkee onelako jende jakitun ustekoak. Fedeko gauzeen sinisgarrirako egin dituala Jangoikoak mirari andiak, nork uka lezake ? Ala bada 
egin ditu mirari asko bekatariak zuzentzeko bizitza onera, obligatzeko ondo konfesatzera ta komulgatzera" (CC hitz. XI).

Zinez ugariak dira etsenpluak, batzuetan bizpahiru segidan. CBn orotara 18 bat bai, labur eta luze. Gehienak Eskritura Santutik apartekoak : a) Elizako Gurasoenak (S. Agustin, S. Juan Chrisostomo, S. Gregorio, S. Antonio Padoa, S. Vicente Ferrer edo S. Bernardino Senakoren adibideak ekarriz, CC hitzaur. X). b) santu-santen bizitzatik atereak ("Irakurten da X santu/santaren bizitzan..." aurkezpenarekin. c) badira Eskritura Santu edo Bibliako zenbait ere (CB 122, 236). Laburrak ("ejenplotxoak") dira batzuk, luzeagoak beste batzuk ("gertaerak" ere deituak, ez gero ipuinak). Mota ugari dago : negargarriak, azkorgarri edo edifikagarriak, atsegingarriak, harrigarriak, beldurgarriak eta mirazkoak. Gero, bada beste etsenplu mota bat: Bibliako pertsonaien gertaeren aipamena. Horiek laburrak dira (adib. Susana CB 74 ; Olofernes, CB 335).

Mogel ez da bakarra, etsenpluez baliatzen; halatsu jokatzen du J.B. Agirrek. Horretan ere Kardaberazen bideari jarraitu zioten, hark ere etsenpluak eta dotrina elkarrekin lotzen baitzituen ${ }^{9}$.

7. Erretorika figuren artean zinez ugariak dira, alde batetik, irudiak eta konparazioak, eta bestetik, hipotiposia edo deskripzioa. Irudi eta konparazioak biziak dira beti, batez ere $\mathrm{CBn}$, eta bere garaiko gizartetik atereak, baserri-, itsas-, merkataritza-girokoak.

"Zenbat, zakur amurratuak baño pozoi geiago duten gizaseme, dabiltza kale, karrika, edo plaza orietan usikitzen duteenak anima itz labañakin, esku askatuakin ? Eta agindu alabai irten dezatela etxetik oen ortzetara joateko ?" (CB 253).

Irudiaren ondoren, aplikazioa jarri ohi du ("Ala bada X-ek ere..." edo antzeko sarrerarekin).

“Jaurtikitzen badiozu zakur bati arriarekin, zakur eroak oratzen, ta usikitzen dio arriari, konturik atera gabe arria geldi egongo zela jaurtiki zion eskua geldi egon balitza. Guk ere, oraindik eroagoak, egozten ditugu begiak lurreko gaitzetara, (...)" (CB 287).

Konparazio asko edo gehienak alegorikoak (edo analogikoak) dira, osagai guztiak konparatzen dituztenak.

"Enzun berdintza au. Neguko otzean berotu nairik bidiazti bat sartu zan etxe batean, non zegoan lasta gela bat. Berotu nairik su eman zion etxeari ; etxeko garretatik igaro zan sua beste erriko etxeetara, ta erre ziran etxe asko. Jakin zan nondik irten zuen suak; Justiziak arrapatu zuen lasto suemallea : erriko guziak bere kontra zituen. (...) ta bidaldu zuten bizitza guzirako gaztelu gogor batera. Ala bada Juez Jesu Kristok ere berotu nai duteenai luxuriako suan, nondik igarotzen diran anima askotara txingarrak, itz, akzio, edo beste gauza zatarren bidez, ez die artuko esesio edo aitzakiarik, ta bialduko ditu infernuko presidio, edo gaztelu gogorrera bekatu bideak ematen dituztenak." (CB 315-316).

Usu liburu santuetako aipamen bateko konparaziotik abiatzen da idazlea, konparazio hori bera garatzeko eta azaltzeko.

“eskribiturik dago desegingo ez diran letraakin : Ez eman gauza santua zakurrai, ezta ere

9 - Aita San Ignacioren Egercicioen gañean Afectoac, beren Egemplo, ta Dotrinaquin : edo Egercicioen IIen Partea. Iruñean : Liburuguille Antonio Castilla-ren echean. 1761.-Ondo iltcen icasteco, ta ondo iltcen laguntceco (...) bearren diran Dotrina, ta Egemploetan. Egercicioen Irugarren Partea. Uriarte-Lecinaren arabera, 2. ed. Iruñea A Castilla-renean, 1765 ; 3.a Tolosa, La Lama-renean, 1790. 
arri preziosorik egotzi ganadu beltz, edo urde zatarrai. Ezda bekatari, geiago irabazi duenik zakur, ta urdearen izena, nola dan ordia. Ordia ta urdia gauza bat dira. Orditzen diran askok trokatzen dituzte edanak, zakurrak jana bezala. Ekusten dira orditu asko eroririk, ta zikindurik lokaitzetan urde zatarra bezala. Eta oei komunio santua eman ? (...)" (CB 334).

Adibide honetan ikusten daiteke nola figurak elkartzen dituen : bereziki konparazioak, metaforak, hipotiposia, hitz-jokoak... Konparazio terminorik gabekoak edo metaforak ere badira (adib. iturriarena, CB 191), ugari gainera Vidan.

Irudi eta konparazioen lagungarri da, edo bestela elkarren laungarri, hipotiposi, deskripzio edo ekfrasia. Zinez ugaria da CBn ; baita Vidan, esperientzia aszetiko edo mistikoen adierazpenerako. Hipotiposiaren bidez gauzek bizia hartzen dute, eta irudi biziok irudimena ukitzen dute, bihotzeraino sartuz ${ }^{10}$. Hor barne dira etopeia edo erretrato morala, etsenpluak (exemplum), tableaux etab. ${ }^{11}$. Horiek "izpiritugauzak haztagarri, sentigarri, miragarri begientzat eta barne-zentzuentzat" egiten dituzte (Fumaroli : 680) ${ }^{12}$.

Mogelen irudi, konparazio eta deskripzio biziak dotrina azaltzeko baliagarriak dira (nahiz topikoak izan, adib. hordiarena, CB 71, edo hiperbolikoak edo ez behintzat errealistak). Baliagarriak dira ere giroa sortzeko (akumulazioa) esaldi paralelistikoen metatze bidez, eta emozioak edo sentimenduak sortarazteko, bereziki beldurra. Edo ondorioak kaltegarriak edo onuragarriak direla adierazteko (pragmatikotasunaren argumentua).

“Baña dakustenean neskatx mutilzale, bullazale, modestia gabe, ta arpegi jaiki bat, begien arintasunean, itzen nasaitasunean, ta ibilmodu eroan agertzen duena bere biotzean zer dagoan, agur mutilla, agur gizona ; an dira eskukak, an apa laztanak, an itz lotsagarriak, an zer ez ? Beraz emakumeak galtzen dituzte anima asko beren nasaitasunakin. Beraz erorten dira eskandaluko becatu kaltegarrian, ta dira deabruaren eizariak." (CB 307).

“Aberastu nai dutenak, nolako bide gogorretan sartutzen ez dira ? Ekustea da merkatari asko beti paperak beltzitzen, egunik geienak daramez kontu ateratzen : batean poza, bestean beldurra. Egiten dituzte askok irabazi oker ta bide gabeak; konzienzia deadarrez, ta onen oiu ta kezkak ito ezinik. Lapurretakin aberastu nai badue, nolako asmo ta mausa gaiztoak estaltzeko logreria edo irabazi txatarra! Ala bada, egia garbi garbia da, aurrez daramezala askok infernuko peneen asipenak mundu onetatik, Jangoikoren legearekin kausio edo konturik egin gabe bizi diranean.

Ori horrela bada ere askorekin, esango zait, beste asko bizi dira pake galantean osasun ederrarekin, ezeren palta gabe, mandamentu santuak ausia gatik. (...)" (CB 76).

8. Azken adibide honetan eta ondokoan ikus dezakegunez, entzuleekiko elkar aditzea indartzen duten figurez baliatu ohi da Mogel dotrina azaltzerakoan.

"Zer ? Kendu nai dizkiguz jaieguneko olgantza edo dibersio garbi inozenteak ? Danzarik egingo ez degula leku agirietan elizakoak eginda ? Nai gaitu iduki edo etxeetan sarturik edo

10 - L'hypotypose est une figure qui peint l'image des choses dont on parle, avec des couleurs si vives, $\mathrm{qu}^{\prime}$ on imagine les voir de ses propres yeux, et non simplement en entendre le récit. Et c'est en quoi consistent principalement la force et le pouvoir de l'éloquence, qui ne domine point assez pleinement, et qui n'a pas tout le succès qu'elle doit avoir si elle frappe simplement les oreilles sans remuer l'imagination et sans aller jusqu'au coeur.", Rollin, Ch., Traité des études... aip., 281.

11 - Erretratoak idatzi zituen Kardaberazek ere ; Justuen Ispillu Arguia. Santuen Erretra to bicia. Santucho Gazte biren, S. Luis, ta S. Estanislaoren Miragarrizco bicitzaren Berrion laburrac. Eta Santucho Gozo bien Bederatziurrenac: Gazteen Probechuraco. Iruñeco : Antonio Castillaren Echean. 1764. Kardaberazen eragina ote dago Mogelengan erretrato bizen erabileran ere ?

12 - Fumaroli, Marc, L'âge de l'éloquence, Albin Michel, 1994. 
bidaldu eremuren batera inork ikusi ez gaitzan ? Jai egunetan olgatuko ezpagera, noiz olgatuko gera ?" (CB 218).

Esaterako, irakurle edo entzulearen erantzun edo eragozpenez baliatzen da, elkarrizketa itxurak eginez (communicatio), horiei hobeki erantzuteko ("G. Esan beza ni duen guzia, baña ez du siniseraziko (...)", CB 316 ; "Badaquit esango didatela $(. .)$, CB 71 ; ). Eta batez ere galdera erretoriko, apostrofe, prosopopea edo pertsonifikazio eta abarrez. Apostrofe mota ugari darabil : irakurle edo entzuleari zuzenduz "Ikusten dezu, kristaua, ..." tankerakoen bidez; edo besteren diskurtsoa jasoz, edo madarikazioen bidez, edo oihu edo esklamazioen bide $z^{13}$. Jakina, figura horiek elkarrekin ageri dira sarri-sarri. Hona zenbait erakusburu.

“Lapur batek kendu balizkitzu etxean dituzun guztiak, ta largatzen bazaitu ezer gabe, paketuko ziñake lapur ark eranzuteaz, ezdala zure etsaia, zure gaitzik nai ezduela ? Zer eranzungo ziñoke ? A traidorea! Anbeste ostu, anbeste kalte egin, ta nai ez deala nire gaitzik ?" (CB 314).

(gertaera bat kontatu ondoan) "O emazte errukarri alako senar ordi ta ardaotiak dauzkatzutenak ! Zertako dira zuen biraoak ? Nai dezute infernura jetsi senar gaiztoekin ? Obe ez dezute aitatu dedan emazteak bezela eskatu Jangoikoari ondu ditzala zuen senarrak ? Biraoka emaztea, umeak ernegu ta gorroto bizian, senarra ordituta, esan dezakete egiaz, nere etxea infernua da. Infernus domus mea est." (CB 340).

“O lotsatzeko gauza! Jaikiko balira euskal-errietako lengo señora ta dama oraingoen asabak, ta ikusiko balituzke beren ondorengoen buruetako asmoak, ta korputz-janziak, zer esango lukee ? Oraingo mirabeak arroago janzirik dabiltza lengo etxeko-andra andikiak baño. Larga nai diot gai oni alperrik nekatu gabe, ta bakarrik orain esango diet, galtzeen dituztenak animak janzi arroegi, ta modestia gabeakin, ematen duteela gaitzerako bidea, zeña dan eskandaloa." (CB 306-7).

Elkar aditzearen indargarrizko figurak, hizketa-estiloaren adierazgarri dira. Halaber jendearen ahoko esanak txertatzea diskurtsoan, idazlea haiezaz baliatzen baita bere jardunari sinesgarritasuna eta bizitasuna emateko : adib. juramentu, maldizio, "hizkune txar" eta mehatxuak, horien euskarazko adierazpide eginak jaso eta txertatzen baititu Mogelek naharo eta xeheki (CB 116, 120, 121, 138, 139, 140, $145,151,152,153,154,157,158,159,160,162,164,165,167,288)$. Edo jendearen erasiak ("Ona emen beata moda berriko bat, egun gutxiko santa (...)", CB 304), zuzeneko elkarrizketak (CB 235), nahiz besteen esanak zehar bidez (CB 127, 172). Halaber atsotitzak (Arejita : 1994 : 30-31). Edo hitanoaren erabilera (gizonezkoena nahiz andrezkoena, CB 252, 314). Edo umore tantoak (CB 172).

Bestalde, figura horiek eta beste batzuk hizlariak bere pasioak (pathos) adierazteko eta irakurle/entzuleengan emozioak sortarazteko (movere) erabiltzen ditu. Emozioak sortarazi nahia batez ere hitzaldiaren bukaeran gertatzen zen batez ere (hots, kapitulu bukaeran), baina ez bakarrik hor.

Beste pentsamendu-figura batzuez ere baliatzen da Mogel kristau dotrina azaltzeko : adib. digresioaz, batez ere euskaldunez mintzatzean : asaba zaharren monoteismoa ( $C B$ 92) edo Konbentzio gerran gaizki erabiliak izan omen ziren elizgizonekiko errespetua gogoratzeko (CB 93).

10. Hitz, hots eta hizkuntza- edo idazkera-egiturei dagozkien figurak ere zinez baliatzen ditu Mogelek dotrina argiago azaltzeko. Adib. sinonimia, antonimia eta paralelismoak ugariak dira.

13 - Oihu edo esklamazioak Mogelek ongi ezagutzen zituen Sta Teresak eta Done Joane Kurutzekoak usu erabili zituzten, hain zuzen. 
"esan zion ondo ta eraz bizi zanari nekez ta premian bizi zanak" (CB 194).

Edo hitz jokoak (ik. 7. atalean ordia eta urdiaren artekoa). Egitura-figuren artean aipagarri dira antitesia eta hiperbatona ; gutxiago erabiliak dira hendiadis edo zeugma.

“onbide, bere animaren kargua duenak eman nai dionik, ez artzea (CB 193).

“esan zion Santa Teresak anima agertu zitzaion, ta zeruzale bati” (CB 192).

Lehena adibidean ageri den perpaus erlatibo bereziaren erabilera ugaria, Mogelen hizkuntz ezaugarrietarik nabarmenetariko baten erakusle da. Halaber aditz aurreratzea edo adizki trinkoa perpaus buruan, ba- gabe, jartzea.

“Dirudi jai egunerako kanpae, edo Eskilloiak jotzea dala bekatuaren gerrara jootzea" (CB 216).

Figura asimetriko eta joskera ez ohikook, simetrikoak eta ohikoak orekatzeko dirateke, eta idazlearen estilo gogoa erakusteko ere.

\section{Mogel katekistaren erudizioa edo jakintza-oinarriak : autoritateak eta aipamenak}

1. Mogelen filosofia ikasketetan ezagun da pentsamenduaren historia ongi ezagutzen duela, testu, aipamen eta esandakoen iturrien aipamen zehatzen bidez. Hain zuzen, B. Pou jesuita irakaslearen filosofia liburuaren ale batzuk behintzat, Mogelen latinezko hitzaurre batekin (latinez baitziren ia ikasketa guztiak) argitara ziren $^{14}$. Hitzaurre hori Xabier Munibe Peñafloridako kondearen gorazarrezkoa da eta hor ezagun du Mogelek ikasi filosofia zientzia esperimentazioari irekia zela. Izan ere, liburuko azken kapituluetan ageri denez, Metafisika ez ezik Fisika -Newon, Kepler- eta Fisiologiaren hastapenak ere irakasten ziren. Filosofiaren historiako lehen eskuliburutzat hartzen dute, eta egilea letren berrindartzailetzat (Martinez dela Escalera : 1982 : 289-304).

Filosofiaren historiako liburu horretako autoritate batzuk, Mogelek bere liburuetan ere aipatzen ditu : adib. S. Inazioren bizitza, Vives, Rollin, Calmet, edo filosofian maisuak ziren Suarez eta M. Cano, edo historian Estrabon edo Mariana ${ }^{15}$. Gero, literaturaren historiako zenbait idazle ere ageri dira, pentsamendua landu dutenak, adib. Horazio, Dante, Petrarca, Bocaccio, Montaigne ; azken honen Entseiu Mora lak "ateismoaren hazi" omen ${ }^{16}$.

14 - Theses Bilbilitanae Institutionum Historiae Philosophicae. Libris XII Comprehensae. Bartholome Povii e Societate Iesu in Seminario Bilbilitano Philosophiae Professoris Institutionum Philosophicae. Lib. XII. Quos defendebat Ioannes Antonius Moguel eius discipulus Semin. Bilb. Alumn. Bilbili anno MDCCLXIII. Typis Ioachimi Estevanii).

15 - Hona aipamen batzuk : Vita Ignat., ap Lib. I, cap IV). Rollin, Rat. Disc. Et docend. T. IV, pag. 255. Lib. I, cap IV). Suarez (lib. X, cap XI). Hona Estrabon-en aipamen bat, Pouren liburukoa, gero Mogelek Peru Abarka-ren hitzaurrean aipatuko duena, turdetanoen kulturari buruz : "Strabo enim a de litteris turdetanorum memorat antiquissimis, qui inter Hispania e populos sa pientia putantur excellere, et littera rum studiis utuntur, et memorandae vetusta tis volumina habent, poimata leges versibus conscriptas e sex annorum millibus, ut aiunt. Ego vero tantum non accipio, quantum turdetanis Strabo dat. illud mihi sumo, sapientiam hispanorum antiquissimis viguisse temporibus, quam si deletis monumentis omnibus, litteris etiam nummorum antiquissimorum incognitis, vel describere, vel recensere non possumus; propterea non negare debemus." Lib III, cap XI).

16 - Michaël, quidem Montanus, natione gallus, an. MDXXX. in lucem editus, egregie artibus doctrinae expolitus, edidit Tentamina Moralis, semina atheismi. (bazterrean : Michel Montanus dubiae famae ethicus eclecticus), Lib. X, cap XII, 232. Ohar bedi bestalde, Pouk pentsalariak nongoak diren, zein nazio edo herrialdetakoak diren esaten du, eta Espainiakoen kasuan zein hiritakoak ere, bere eta kideen baleartasuna aipatuz, R. Llull katalanaren en filosofia etab. 
Teologiako ikasketei dagokienez, badakigu Mogelek Teologia eskolastikoa, dogmatikoa eta morala ikasi zueela, apaiz izateaz gainera jakintza edo erudiziora eman zela, apaizen arteko Solasaldi edo Konferentzia moralen arduraduna izan zela, Inkisizioan liburu azterlari izateko eskaeran bere curriculum-ean jakinarazi zuene $z^{17}$. Jakina da ere hizkuntzalari eta historigile jakintsuekin harreman zuzenak edo gutunbidezkoak izan zituela euskararen gainean (Vargas Ponce, Hervas, Astarloa, Humboldt).

2. Mogelen erlijio liburuetako jakintza-iturriak eta oinarriak aipamen, zita edo zitazioetan nahiz ziten parafrasietan ageri dira. Latinezko aipamenak ugariak dira : batzuk luzeak (CB 199-200) ; laburrak beste batzuk ; horietako batzuk, egile aipaturik gabeak izanez, agian harenak dira (CB 203, 204, 227). Batzuetan latinezko aipamenaren barruan aipatzen da autoritatea, eta bazterrean aipamena zehatzago. Askotan latinezko aipamen labur batekin zirtatzen du azalpena. Aipamen batzuk zuzenak dira, beste batzuk zeharbidezkoak ("X-ek dioenez...", "esan zien San Pedro Crisologoc", CB 228).

Ondoko lerroetan aztertuko dugu zein diren CBn ugarienik ageri diren aipamenak, haren teologia joera aztertzeko asmorik bat ere gabe ordea, egunen batean norbaitek zehatz aztertuko duen uste eta nahiz.

3. Biblia edo Eskritura Santuko aipamenak dira ugarienak. Testamentu zaharretik ondoko liburuetakoak : Exodo, Profetak (gehienetan Jainkoa edo Espiritu Santua mintzo da profeta baten ahoz: Jeremias, Malach., Esdras, Joel eta batez ere Isaias), Proberbioak, Psalmoak, Deuteronomio, eta batez ere Ecclesiastes. Askoz aipamen gutxiago hartzen ditu ondokoetatik: Job Santua, Jakintsuen liburua (Sap.), Levitiko edo Genesis ${ }^{18}$.

Testamentu Berritik : S. Lukas eta S. Joan ebanjelariak (Jesukristok haien ahotik) eta batez ere Mateoren liburutik; ebanjelarien aipamenak etengabeak dira CO eta Vidan ere. San Joan ebanjelariaren Apokalipsia noizbehinka baino ez, orobat haren epistolak $^{19}$.

Apostoluen gutunetatik : S. Pauloren epistolak Timoteori, Filipori, hebrearrei, erromatarrei, galaziarrei eta batez ere Thesalonika, Efeso eta Korintiokoei. San Paulo da aipatuena Mogelen dotrina azalpen liburu mamitsuenetan (batzuetan "Apostoloa" izendatua da : "dio Apostoloak", CB 271) ${ }^{20}$. Gero badira aipamen batzuk Santiago eta San Pedro apostoluen epistoletatik ${ }^{21}$.

17 - “después de haver seguido su carrera de Filosofia, Theologia escolástica, dogmática, y moral, recivio el sagrado carácter del Sacerdocio, y que casi todo su tiempo desde la edad de veinte y cinco años hasta el de presente, que ha cumplido la de cuarenta y ocho años, se ha empleado en el Ministerio de cura de almas, en el que continua procurando cuidar de sus obligaciones, dedicandose tambien a los ramos de la erudición de la disciplina_eclesiastica ; (...)" (Ilmo Señor Arzobispo de Selimbria, Inquisidor general de los Reinos, y Dominios de Su Magestad Catolica. Marquina y junio 15 de 1794, in Garate, J., "Cinco cartas inéditas...".

18 - Hona aipamenak (orrialde guztietakoak jaso gabe ordea) : Exodo : CB 195, 208, 210, 211, 303. Genesis : CB 196. Profetak: David CB 214 ; Jeremias CB 216, 318 ; Malach. CB 227 ; Isai CB 262, 304, 329, 333 ; Esdras CB 305 ; Joel CB 340 ; Agg CB 213 ; Profetak: Vida 12. Prov: CB 240, 251, 254, 256, 276, 335. Sap : CB 263, 278. Psalm : CB 248, 264, 287, 289(2), 314, 324, 332.Job : CB 228, 340. Eccles.: CB 218, 219(2), 240(2), 245, 248, 255, 268(2), 276, 328. Deuteron. : CB 240, 264, 340. Levit. : CB 240, 264, 340.

19 - Matheo : CB 280(2), 283, 288, 289, 290(3), 293, 298(2), 301, 313, 334. S. Luk. : CB 234, 263, 271, 289, 340. S. Joan. : CB 221, 274, 285, 298. Apok. : CB 307. S. Joan. Epist. : CB 322.

20 - Epist. : Thesal. I : CB 215 ; Thesal. II : CB 271. Efes. : CB 234, 254, 268, 331. Timot. : CB 266, 269. Philip. : CB 281, 325. Hebr. : CB 261, 328. Rom. : CB 281, 328. I Corinth. : CB 283, 291, 300, 309, 330. Galat. : CB 305(2). Beste (S. Paulo) : CB 222, 241, 251, 259, 264, 265, 269, 273. Vida, Prol 1, 4,11

21 - Santiago : CB 273, 294, 316. S. Pedro : CB 316. 
4. Elizako Doktore edo Gurasoak. Rollin-en arabera Elizako Gurasoen irakurgaiak ziren : egia eta egiaren probak, arrazoibideak edo hastapenak (printzipioak) eta ondorioak, erregelak eta aplikazioak, pentsamentuak eta horien adierazpideak (Rollin : $1841: 351$ ).

S. Agustin-en liburuetatiko aipamenak dira Eliz Gurasoen artean ugarienak (Aitorkizunak, Bakarrizketak). Usuak dira ere Vidan eta COn ("Handia", "Jakituna", "Egiazalea" eta halako kalifikatiboekin maiz) ; hain zuzen, Aitorkizunak-en eredura idatzia da Vida, espreski dioenez ${ }^{22}$. Ondoren, S. Juan Krisostomo eta San Anbrosioren aipamenak ageri dira maizenik. Askoz gutxiago beste Elizako Doktore eta santu batzuenak: S. Jeronimo, San Gregorio, S. Pedro Damiano, S. Bernardo, San Buenaventura, San Hilario, San Antonio abata, Santo Tomas, San Francisco Sales, San Dionisio Areopagita ${ }^{23}$.

5. Santu-santen bizitzari buruzko liburuetatik jasotako aipamenak ugariak dira. Haien bizitzako gertaera edo esan bat aipatzen dute, gehienetan zeharbidez ("Erakurten da X santu/santaren bizitzan", "esan oi zuen X santu/santak" edo antzeko aurkezpen batekin). Egilea nor den beti ez da ageri eta baliteke Mogelek bigarren eskuko iturri batetik hartuak izatea. Hona aipatuak : Sta Maria Egipziakoaren bizitza (Vida Prol 9, 10, S. Juan Columbinok irakurria ; id. 33) ; Beata Beronika Binaskoren bizitza (ap Boland, CB 192-193) ; San Mauriloren bizitza ; San Leofrido Abataren bizitza, Constantino enperadore santuak esana, San Luis Frantziako erregeari bere amak esana, S. Atalo etab. ${ }^{24}$.

Bereziki San Inazio Loiolako “euskaldun guzien honragarria” (CB 314) izendatzen duenaren aipamenak franko dira, zeharbidezkoak baina Mogelek ezagutzen zuela darakusatenak (CB 306). S. Inazioren Bizitza irakurtzen zuen M. Ignazia Ubilla beatak Mogelen gidaritzapean (Vida 35).

Beste santu batzuen izenak ere aipatuak dira : San Antonio Florenziakoa ; San Vicente Ferrer, S. Luis Gonzaga, S. Estanislao Koska, S. Felipe Neri, etab. ${ }^{25}$. Santusanten aipamenok, ugariak zinez, Mogelen zaletasuna, santu-santen bizitzak irakurtzekoa, erakusten dute.

6. Aszetika eta mistikako liburu eta idazleen aipamenak gehienetan zeharbidezkoak dira, ugariak eta laudagarriak, Mogelek ongi ezagutzen zituela frogatzen dutenak. Batez ere Done Joane Kurutzekoaren eta Sta Teresarenak CB, CC

22 - “Ha sido muy frecuente en multitud de santos, santas, y venerables siervos de Dios el escribir de su puño, ya sus defectos, ya las misericordias o beneficios que recibieron de la benéfica mano del Señor. ¿Qué ha perdido Agustino con el libro de sus Confesiones ? (...). A egemplo de tan grande santo escribió la $\mathrm{D}^{\circ}$ Maria Ignacia sus defectos, asi para su confusión, como para gloria de Dios." (Vida de ...25, eskuizkr.).

S. Agustinen aipamenak : CB 220, 257, 336 ; Vida Prol. 2, 21, 30, 35, 50, 51(2), 57 ; CO hitzaur. 3.

23 - S. Juan Chrisost. : CB 220. S. Ambrosio : CB 97, 217, 220, 247, 252, 276. S. Bernardo : Vida Prol 6. S. Gregorio : CB 105. S. Buenaventura : CB 117. S. Pedro Damiano : CB 135. S. Hilario : CB 170. Sto Tomas : CB 215. S. Jeronimo : CB 265. S. Antonio abata : CB 316(2). S. Pedro Crisologo : CB 228. S. Frantzizko Sales : "dio San Francisco Sales pakezaleak (...)" (CB 297).

S. Dionisio Areopagita : "Sarri irakurri det iñoiz aaztu etzatan San Dionisio Areopagitaren esan au ; Jangoikozko gauzeen artean jangoikozkoena da la, bear egitea animaak salbaziora zuzentzen" CB 321).

24 - "Ezdira ordea kontatu gabe largatzekoak San Maurilo miragilla andiaren bizitzan kontatzen diran gertaera oek." (CB 212). "Erakurten da San Leofrido abataren bizitzan (...)" (CB 213). "Erakurten da anziñako eremutar, edo padar santuen bizitzetako Libruan, (...)" Ex Vitis PP (CB 337). "esan oi zuen Konstantino enperadore santuak (...)" (CB 265). "San Luis Errege Franziakoari (...) esan oi zion bere ama onak (...)" (CB 249). "Onela eranzun zion San Atalo martiriak fedegabeko agintariari galdetu zionean (...)" (CB 114-115). 25 - S. Antonio Florenziakoa : CB 217. S. Bizente Ferrer : ibid. S. Luis Gonzaga, S. Estanislao Koska : CB 228. S. Felipe Neri : CB 319. 
eta bereziki Vidan. Lehena mistikan maisutzat hartua da ("doktore mistikoa") ${ }^{26}$, eta bigarrena teologia aszetikoan ${ }^{27}$. Beste santa batzuen bizitza-liburuen aipamenak : Sta Maria Magdalena Pazis eta Santa Rosa Limakoaren bizitzak ${ }^{28}$. Horiek guztik Mogelen aszetika zaletasuna erakusten dute.

7. Beste erlijio-liburu eta egileetatikoak : Trentoko Kontzilioa, Astete, Kenpis, Belarmino kardinala, A Lapide, Benedikto XIV, Alfonso $\mathrm{M}^{\mathrm{a}}$ Ligorio, Aita Kalataiud, Tirino, Maldonatus. Zehaztasunik gabe : Salamankako Konpendioaren egilea, predikatzaile santu bat ${ }^{29}$.

Beste liburu batzuk, meditazio-gaiezkoak ere aipatuak dira : adib. M. Ignaziak irakurriak (edo Mogelek irakurraraziak, pentsatzekoa denez) : aipatu S. Ignazioren bizitzaz gainera, Abanciniren meditazioak eta Fr. Luis Granadakoaren liburua ${ }^{30}$.

8. Liburu eta egile profanoetarikoak : "erromatarren liburuak" (zehaztu gabe), Zizeron eta batez ere Luis Vives ${ }^{31}$. Bestalde, ez da ahaztu behar Pascal, haren "gogamenen" zati bat bederen itzuli baitzuen Mogelek.

Beraz erlijio liburuen ezagutza eta erudizio handia erakusten du Mogelek, bereziki ondoko irakasle eta liburuetatiko aipamenetan : S. Pablo, S. Mateoren ebanjelioa, Testamentu Zaharreko liburuak (Exodo, Profetak, Psalmoak,

26 - "Yo aconsejara a todo confesor, que lea y relea las obras de San Juan de la Cruz, que no salga de las grandes documentos que da este doctor místico, y que procure guiar a las almas por el camino seguro de la desnudez, ( ...)" (Vida 52). "No me cansaré en repetir, que lea con atención y relea las grandes doctrinas del dicho doctor mistico y verá que (...)" (Vida 52).

27 - "Qualquiera que lea en la Introducción de la vida que escribió Santa Theresa con qué dolor se queja de que no la hubiesen permitido decir con claridad sus grandes pecados, y ruin vida (Mogelek berak azpimarratua); que ruega a los lectores del discurso de su vida, (...)" (Vida 26).

“Por ejemplo, quien podrá negar que fuese voz sobenatural aquella admirable habla, con que fue esta sierva del Señor llamada a la penitencia ! (...). Las hablas divinas obran lo que dicen; es al mismo tiempo palabra y obra, dice la Maestra de la teología ascética : sean de devoción, sean de reprensión causan luz, temor santo, y una estimación pacífica." (Vida 50).

"Si todo se ha de despreciar, dar por embuste, embaucamiento, producción de una fantasia recalentada, o ilusión demoníaca, quémense las obras de Santa Teresa, de San Agustín y otros muchos santos y santas que han publicado lo que ha pasado por sus almas y las ajenas" (Vida 51).

28 - "Irakurtzen baditugu Santa Teresa, Santa Maria Magdalena Pazis, ta Santa Rosa Limacoren bizitzak, ekusiko ditugu sarturik urte osoetan eriotza bera baño ere gogorrago ziran espirituko illuntasun ta agortasunetan" (CB 85).

29 - "Eliza Ama Santak erakasten diguna Trentoko Konzilioan" (CB 95). "Asteteren dotrina liburu labur baina urrezkoak" (CB 266). Kempis : Vida 38. "Ala dio Belarmino kardenal beneragarriak bere urrezko doktrina liburuan" (CB 230). Benedictus XIV Instit. LIV pag.32 num. 27 (CB 200). (Alfonso M. Ligorio) "Ona nola ebakiko dizun zure aituezina jakituria andiko Teologo batek." Ligori. De $3^{\circ}$ Dec. Prec., + latinezko esaldia (CB 202). Aita Kalataiud : "Aita Calataiud Misionista enzunak (...)" (CB 102) ; Videatur Calataiudis in Doctrina de Pueroroum Confessionibus (CB 184). Auctor Compendii Salmaticensis : Part $2^{\circ}$, tit. I Cap II (CB 209). Predicadore santu bat : CB 317. Tirino : CB 276. Maldonat. in cap. 16. Lucae (CB 327).

30 - "Dio Inazia Ubilla beatak: "Me preparaba con la lectura de algun libro, y era o el de las meditaciones de Abancini, o el de Fray Luis de Granada." (Vida 36). "La materia más común de la meditación era la vida y la Pasión de Jesús, que la leia en Abancini." (Vida 38).

31 - Erakurten da erromatarren libruetan (...)" (CB 258). Zizeron : CB 222. L. Vives : Lud. Vives. Lib. VIII. C.9. (S. Agustinekin batera aipatzen du : "lenbiziko españarrak (eta ziran guziak orduan euskaldunak) ezagutzen zuteela Jangoiko bakar gauza guzien egillea,...", CB 115). Vives aipatua da Pou-ren Institutiones liburuan, esan dugunez (Lib I Cap I ; Lib. I, cap II ; Lib III, cap XII). Gogora bestalde, Peru Abarca ren hitzaurrean aipatua dela, haren ereduz asmatu baitzituen liburu horretako solasaldiak. Mayansekin batera aipatua da hor, hark ere bere erretorika liburuan goraipatzen baitzuen : "El célebre y nunca bastantemente alabado Juan Luis Vives tuvo por estrechos los limites de la Retórica común y los ensanchó grandemente, imitando a los antiguos más sabios en sus tres libros del Arte de decir llenos de útil erudición, y de prudencia civil." (Rhetorica de Don Gregorio Ma ya ns i Siscàr. T. I. En Valencia : Por los Herederos de Geronimo Conejos, enfrente de San Martin. Año 1757.) 
Ecclesiastes), S. Agustin, Sta Teresa, Done Joane Kurutzekoa eta beste santu-santa askoren bizitzako liburuetan. Halako erudiziorik ondoko idazleetan (Fr. Bartolome, Fr. P. Astarloa, J.B. Agirre...) agertzen denez, eta batez ere zer teologia-joera erakusten duen Mogelek, jakingarri da.

Azken hitz, hona laburki artikulu honetan esanak : dotrina hertsia da Mogelek azaltzen diguna, liburu santu eta santuen liburuetako jakintza oparoan oinarritua, eta kontakizunek, irudi eta deskripzioek, bai eta entzuleekiko elkar aditzezko figurak eta hizketa estiloak gozatua.

\section{Bibliografia}

- Altzibar, X., Bizkaierazko idazle klasikoak. Mogeldarrak, Astarloatarrak, Frai Bartolome : nortasuna, idazla nak, grafiak. Bizkaiko Foru Aldundia, 1992, 117-128. or.

- Arejita, A, Juan Antonio Mogel. El Catequista Bascongado. Cristau Eracasle Euscalduna. Irugarren Zati edo Partea : Jangoicoaren Legue, ta Eleizaco Mandamentuen gañean, Labayru Ikastegia-Bilbao Bizkaia Kutxa, 1994. "Eracasle Euscalduna-ri gainbegiratua" hitzaurrearekin (9-60).

- "Juan Antonio Mogelen Versiones Bascongadas", Litterae Vasconicae, 9, Labayru Ikastegia, 2004, 65-117.

- Fumaroli, Marc, L'âge de l'éloquence, Albin Michel, 1994.

- Garate, J., "Cinco cartas inéditas de Juan Antonio Mogel”, in Ensayos eusca ria nos, Bilbao, Neilly, 1935, 227-229

- La época de Pablo Astarloa y Juan Antonio Mogel, Bilbao, Imprenta Provincial de Vizcaya, 1936.

- Martinez dela Escalera, J., S.J., “Ciencias y letras entre los jesuítas dela Corona de Aragón (1747-1767)", Pa peles de Jesuíta s III, Miscelánea Comillas, XL, 1982, nº 77, 263-325 or.

- Rollin, Ch., Traité des études ou de la manière d'enseigner et d'étudier les BellesLettres. Paris, L. Hachette, librairie de l'Université, rue Pierre-Sarrazin, 12. 1841 (XVIII. mende erdia baino lehenagokoa da Rollin-en liburua). 